\title{
Bacterial Vaginosis: An Underestimated Cause of Unexplained Infertility
}

\section{Faruqui AA*}

Department of pharmacology, Clinical Pharmacologist, India

\section{Mini Review}

Volume 3 Issue 2

Received Date: July 18, 2018

Published Date: August 02, 2018

*Corresponding author: A.A. Faruqui, Department of pharmacology, Clinical Pharmacologist, 504A, Opp. K.B. Bhabha Hospital, Waterfield Road, Bandra (W), Mumbai-400050, Maharashtra, India, Tel: 9322429615; Email: drfaruqui@gmail.com

\section{Abstract}

Bacterial Vaginosis (BV) characterized by symptoms of vaginal malodor and slightly too moderately increased white discharge, which appears homogeneous, with low viscosity and smoothly coats vaginal mucosa. The vaginal fluid of women with bacterial vaginosis is characterized by markedly increase prevalence and concentration of G. vaginalis, Mycoplasma hominis and several anaerobic bacteria's. The normal acidic lactobacilli is the constitute most of the normal vaginal flora and help to protect against certain cervical and vaginal infections. L. gasseri, L crispatus produce large amounts of $\mathrm{H}_{2} \mathrm{O}_{2}$ and inhibits the growth of $G$. vaginalis while L. rhamnosus increases colonization of lactobacilli and decreases the recurrence of BV.

Studies have reported a high prevalence of BV in both non-tubal and unexplained infertility.

The most common oral treatment for BV in both pregnant and non-pregnant women is metronidazole. Therapy with metronidazole or clindamycin alters the vaginal flora and predisposes the patient to development of vaginal candidiasis. Recurrence rate of BV remains high with use of antimicrobials and such treatments are not designed to restore the lactobacilli. Antimicrobial drug resistance remains a root cause for BV recurrence. Probiotic supplementation as part of a broader lifestyle intervention aimed at improving fertility as the potential for side effects is nearly nonexistent, and there are reasons to think that it could be helpful.

Keywords: Bacterial Vaginosis; Probiotic; Lactobacilli; Fertility

\section{Introduction}

Bacterial Vaginosis (BV) is a common disorder of the genital tract in women characterized by an alteration of the normal acidic lactobacilli-predominant vaginal ecosystem with an increase in $\mathrm{pH}$ [1]. The infection is characterized primarily by paucity or depletion of the vaginal lacto-bacilli and their replacement by an outgrowth of different micro-organisms including Gardnerella vaginalis (GV), anaerobic rods, pepto- 
streptococci, and mycoplasma species [2]. Bacterial Vaginosis (BV) is the most common cause of abnormal vaginal discharge among women of child bearing age and is associated with adverse obstetric and gynecologic outcomes [3]. Common symptoms include increased vaginal discharge that often smells like fish, the discharge is usually white or gray in colour, burning with urination may occur, mild itching.

\section{Vaginal Flora in reproductive Indian women}

The microbial species that inhabit the vaginal tract play an important role in the maintenance of health, and prevention of infection. Despite the close proximity of the vagina to the anus, the diversity of microbes present in the vagina is much lower than in the gut. Lactobacilli are the most common, particularly in healthy women [4].

Using molecular-based techniques, it is known that healthy vaginal microflora does not contain high numbers of many different species of Lactobacillus. Rather, one or two lactobacilli from a range of three or four species (mainly L. crispatus and L. iners, but also Lactobacillus jensenii and Lactobacillus gasseri) are dominant, whereas other species are rare \& lower in titer [5].

In a study conducted in 132 women of Mysore, the predominant Lactobacilli species isolated were L. gasseri (46\%), L. crispatus (40\%) and L. jensenii (14\%) [6]. In another study steered by Kiss et al in 200 healthy pregnant women, the most frequently occurring species were Lactobacillus crispatus and Lactobacillus gasseri, followed by Lactobacillus jensenii and Lactobacillus rhamnosus [7].

\section{Vaginal Lactobacillus Microbiota of Healthy Women in the Late First Trimester of Pregnancy}

Majority of cases of BV are asymptomatic and remain unreported and untreated. The role of asymptomatic compared with symptomatic BV in both gynecologic and pregnancy-related conditions have been less studied [8].

\section{Prevalence \& Association of BV with Infertility}

Prevalence of BV among women of reproductive age group is around $31.5 \%$. Low education level and low socioeconomic status is a significant risk factor for bacterial vaginosis with $48.9 \%$ and $40.3 \%$ respectively [3]. Studies have reported a high prevalence of BV in both non-tubal and unexplained infertility [2].
In a study conducted by Singaravelu, et al. over a period of 6 months in 116 women with infertility problems at Sri Lakshmi Narayana Medical College and Hospital Pondicherry, it was observed that women with infertility problems showed abundance of Bacterial Vaginosis (Lactobacillus, 3.5\%) compared to healthy women (Lactobacillus, 27.8\%). Author of the study recommended the screening of vaginal flora as a routine for all women, especially in women undergoing infertility treatment [9]. In another study conducted by Pramanik, et al. in 510 women with manifestations such as infertility, it was found that BV infection is associated with infertility and its absence leads to pregnancy, emphasizing its screening and treatment [10]. In a study conducted by Salah RM, et a.l in 874 infertile females, reported a high prevalence of BV amongst them compared to fertile women ( $45.5 \%$ vs. $15.4 \%$ respectively) [2].

\section{Why BV leads to Infertility?}

Mechanism by which BV may cause infertility includes plasma cell endometritis, tubal motility disorders and auto-immune infertility [2].

\section{Limitations of Existing Therapy}

The most common oral treatment for BV in both pregnant and non-pregnant women is metronidazole. Simoes JA. et al. reported that high concentrations of metronidazole, greater than $5,000 \mu \mathrm{g} / \mathrm{ml}$, completely suppress the growth of Lactobacillus and that concentrations of $1,000-4,000 \mu / \mathrm{ml}$ significantly inhibited the growth of Lactobacillus [8]. Therapy with metronidazole or clindamycin alters the vaginal flora and predisposes the patient to development of vaginal candidiasis. Recurrence rate of BV remains high with use of antimicrobials and such treatments are not designed to restore the lactobacilli. Antimicrobial drug resistance remains a root cause for BV recurrence [4]. The two topical treatments for BV like metronidazole $0.75 \%$ vaginal gel and clindamycin $2 \%$ vaginal cream; result in the resolution of lower genital tract infection but do not treat BV occurring in the upper genital tract [8].

\section{Significance of Probiotics Treatment in BV}

Studies have suggested that the presence of $\mathrm{H}_{2} \mathrm{O}_{2}$ (hydrogen peroxide) producing vaginal lactobacilli may protect against BV by inhibiting the adherence of Gardnerella vaginalis and produce hydrogen peroxide, lactic acid and bacteriocins, which inhibits the growth of bacteria causing BV [11]. 
A review by MacPhe, et al. recommends the inclusion of probiotics as part of the approach to disease prevention and as an adjunct to antimicrobial treatment [12]. Neither the immune system nor antibiotics eradicate all of the microbes; therefore biofilm related infections may be persistent and women with BV tend to have high recurrence rates.

\section{Role of Lactobacilli Strain}

L. gasseri and L. jensenii co aggregate with G. vaginalis (pathogenic bacteria) and block the adherence and / or displace previously adherent strains of G. vaginalis from vaginal epithelial cells. L. gasseri, L crispatus produce large amounts of $\mathrm{H}_{2} \mathrm{O}_{2}$ and inhibits the growth of $\mathrm{G}$. vaginalis while $\mathrm{L}$. rhamnosus increases colonization of lactobacilli and decreases the recurrence of BV [11].

Macklaim, et al. (2015) reported that treatment of BV with antimicrobial therapy and probiotic supplementation, namely Lactobacillus reuteri and Lactobacillus rhamnosus, increased the abundance of indigenous Lactobacillus iners and Lactobacillus crispatus. This observation opens up the possibility of harnessing specific bacterial strains in order to prime the vaginal microbiota in the pre- and peri-conceptual periods [13]. Salah, et al. in his study had found that even after controlling for the different variables which influenced the pregnancy rate in patients with PCOD, BV still remained a significant factor impairing the pregnancy rate [2].

\section{Conclusion}

Bacterial Vaginosis (BV) is an extremely prevalent vaginal condition and the number one cause of vaginitis among both pregnant and non-pregnant women. It is a new cause of unexplained infertility which has probably been underestimated. The high prevalence of $\mathrm{BV}$ in infertile women may suggest either a possible role of BV on fertility or just an association between BV and infertility. It makes sense to at least consider probiotic supplementation as part of a broader lifestyle intervention aimed at improving fertility as the potential for side effects is nearly nonexistent, and there are reasons to think that it could be helpful.

\section{Acknowledgment}

The author would like to express his thanks to Mr. Rahul, M Kakalij and Ms. Kanchan Choudhary for helping to inscribe the manuscript.

\section{References}

1. Charles RB (2010) Obsterics and Gynecology. Chapter 26: vulvovaginitis, $6^{\text {th }}$ (Edn.), pp: 241-245.

2. Salah RM (2013) Bacterial vaginosis and infertility: cause or association? Eur J Obstet Gynecol Reprod Biol 167(1): 59-63.

3. Singh A, Kanti V, Dayal S, Shukla SK, Mishra N (2016) Prevalence and risk factors of bacterial vaginosis among women of reproductive age attending rural tertiary care institute of Western Uttar Pradesh. J Evolution Med Dent Sci 5(43): 2695-2701.

4. Cribby S, Taylor M, Reid G (2008) Vaginal Microbiota and the Use of Probiotics. Interdiscip Perspect Infect Dis, pp: 1-9.

5. Lamont RF, Sobel JD, Akins RA, Hassan SS, Chaiworapongsa T, et al. (2011) The vaginal microbiome: new information about genital tract flora using molecular based techniques. BJOG 118(5): 533-549.

6. Madhivanan P, Alleyn HN, Raphael E, Krupp K, Ravi K, et al. (2015) Identification of culturable vaginal Lactobacillus species among reproductive age women in Mysore, India. Journal of Medical Microbiology 64(6): 636-641.

7. Kiss H, Kogler B, Petricevic L, Sauerzapf I, Klayraung S, et al. (2007) Vaginal Lactobacillus microbiota of healthy women in the late first trimester of pregnancy. BJOG 114(11): 1402-1407.

8. Nelson DB (2002) Bacterial vaginosis in pregnancy: current findings and future directions. Epidemiol Rev 24(2): 102-108.

9. Babu G, Singaravelu BG, Srikumar R, Reddy SV, Kokan A (2017) Comparative Study on the Vaginal Flora and Incidence of Asymptomatic Vaginosis Among Healthy Women and in Women With Infertility Problems of Reproductive Age. Journal of Clinical and Diagnostic Research 11(8): DC18-DC22.

10. Mania-Pramanik J, Kerkar SC, Salvi VS (2009) Bacterial vaginosis: a cause of infertility? Int J STD AIDS 20(11): 778-781.

11. Falagas M, Betsi GI, Athanasiou S (2007) Probiotics for the treatment of women with bacterial vaginosis. Clin Microbiol Infect 13(7): 657-664. 
12. MacPhee RA, Hummelen R, Bisanz JE, Miller WL, Reid G (2010) Probiotic strategies for the treatment and prevention of bacterial vaginosis. Expert Opin Pharmacother 11(18): 2985-2995.
13. García-Velasco JA, Menabrito M, Catalán IB (2017) What fertility specialists should know about the vaginal microbiome: a review. Reprod Biomed Online 35(1): 103-112.

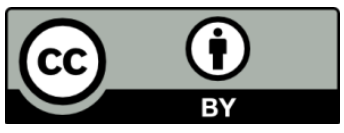

